\title{
AÇÃo de Herbicidas sobre o Crescimento de Estirpes de Rhizobium tropici ${ }^{1}$
}

\author{
Herbicide Action on the Growth of Rhizobium tropici Strains
}

SANTOS, J.B. ${ }^{2}$, SILVA, A.A. ${ }^{3}$, COSTA, M.D. ${ }^{4}$, JAKELAITIS, A. ${ }^{2}$, VIVIAN, R. ${ }^{5}$ e SANTOS, E.A. ${ }^{6}$

\begin{abstract}
RESUMO - O objetivo deste trabalho foi avaliar o crescimento das estirpes de Rhizobium tropici BR 322 e BR 520, utilizadas como inoculantes na cultura do feijoeiro no Brasil, em meio de cultura à base de manitol e extrato de levedura (YM) adicionado de diferentes herbicidas (bentazon, metolachlor, imazamox, fluazifop-p-butil, fomesafen e paraquat). Os herbicidas fluazifop-p-butil e fomesafen foram avaliados puros e em mistura comercial, em concentrações variando entre 0,0 e 49,23 $\mathrm{mg} \mathrm{L}^{-1}$. O crescimento das estirpes de Rhizobium foi avaliado em espectrofotômetro ao longo de 100 horas de incubação, por meio da leitura da densidade ótica, a $560 \mathrm{~nm}$, sendo, posteriormente, convertido em unidades formadoras de colônia por mL. Observou-se que o paraquat foi o herbicida com maior inibição do crescimento das estirpes avaliadas, seguido pela mistura comercial de fomesafen e fluazifop-p-butil. Para os demais herbicidas, a redução do crescimento não foi significativa. De modo geral, a estirpe BR 520 mostrou-se mais tolerante aos herbicidas testados, com exceção do paraquat. No ensaio de concentrações crescentes do fomesafen, isolado ou em mistura com fluazifop-p-butil, não foi possivel determinar o $\mathrm{I}_{50}$ (concentração do herbicida que reduz em $50 \%$ o crescimento do rizóbio); a maior redução, de $31,1 \%$, foi observada para a estirpe BR 322 na máxima concentração testada $\left(49,23 \mathrm{mg} \mathrm{L}^{-1}\right)$ da mistura comercial.
\end{abstract}

Palavras-chave: bentazon, fluazifop-p-butil, fomesafen, imazamox, S-metolachlor, paraquat.

\begin{abstract}
This work aimed to evaluate the growth of Rhizobium tropici BR322 and BR 520 strains, used as inoculant on common bean in Brazil, in yeast extract manitol (YM) medium supplemented with different herbicides (bentazon, metolachlor, imazamox, fluazifop-p-butyl, fomesafen and paraquat). Fluazifop-p-butyl and fomesafen were evaluated pure and in a commercial mixture with concentration varying from 0.0 to $49.23 \mathrm{mg} \mathrm{L}^{-1}$. Cell growth was assessed by optic density readings in a spectrophotometer at $560 \mathrm{~nm}$, being later converted to colony forming units per $m L$. Paraquat caused higher inhibition of cell growth, followed by the commercial mixture fomesafen and fluazifop-p-butyl. For the other herbicides, growth reduction was not significant. In general, BR 520 strain was more tolerant to the tested herbicides, except to paraquat. The herbicide concentration $I_{50}$, (which decreased Rhizobium growth in 50\%) could not be determined in the fomesafen concentrations tested, isolated or mixed to fluazifop-p-butyl. The highest reduction of 31.1\% was observed in BR322 at the maximum tested concentration of the commercial mixture.
\end{abstract}

Keywords: bentazon, fluazifop-p-butyl, fomesafen, imazamox, S-metolachlor, paraquat.

Recebido para publicação em 22.11.2005 e na forma revisada em 4.8.2006.

2 Bolsista CNPq - Pós-Doutorando do Departamento de Fitotecnia, Universidade Federal de Viçosa - DFT/UFV, Av. P.H. Rolfs, s/n, 36570-000 Viçosa-MG, <jbarbosasantos@ yahoo.com.br >; ${ }^{3}$ Professor do Departamento de Fitotecnia da UFV; ${ }^{4}$ Professor do Departamento de Microbiologia - DMB/UFV; ${ }^{5}$ Estudante de Mestrado do Departamento de Fitotecnia - DFT/UFV; ${ }^{6}$ Acadêmico do curso de Agronomia da UFV.

Planta Daninha, Viçosa-MG, v. 24, n. 3, p. 457-465, 2006 


\section{INTRODUÇÃO}

A aplicação de herbicidas sobre culturas que realizam simbiose com bactérias fixadoras de nitrogênio atmosférico pode prejudicar a eficiência na assimilação desse nutriente (Marenco et al., 1993; Novo et al., 1996, 1998; Santos et al., 2005). Tais prejuízos devem-se à interferência do herbicida no metabolismo do microssimbionte, na planta hospedeira ou de ambos, quando em associação (Arruda et al., 2001b). A aplicação de herbicidas, dependendo do princípio ativo ou da formulação, da dose utilizada, dos microrganismos presentes e da sensibilidade destes aos diversos produtos (Royuela et al., 1998), das condições climáticas e do tipo de solo (Silva et al., 2003), pode trazer conseqüências indesejáveis para a microbiota. Acredita-se que a maior interferência desses compostos ocorre quando eles agem sobre a biossíntese de aminoácidos ou rotas metabólicas comuns entre microrganismos e plantas.

Por esse motivo, o uso de moléculas herbicidas e formulações menos agressivas a organismos não-alvos deve ser objetivo de todos aqueles que se utilizam dessa tecnologia para aumentar a produção de alimentos sem, no entanto, comprometer a produtividade e sustentabilidade do sistema.

A capacidade produtiva dos atuais cultivares de feijão é aumentada somente com tecnologia que demanda alta adubação. Nesse sentido, a fixação biológica do nitrogênio pode ser uma alternativa para os adubos nitrogenados, desde que haja manejo adequado para o microssimbionte (rizóbio), visando aumentar a eficiência dessa associação. Nos cultivares utilizados no Brasil, que apresentam boa nodulação, a fixação de nitrogênio representa até $30 \mathrm{~kg} \mathrm{ha}^{-1}$ por cultivo (Mendes et al., 1995).

Trabalhos realizados em outros países (Moorman et al., 1992; Eberbach \& Douglas, 1989; Mallik \& Tesfai, 1985; Schuls et al., 1985) evidenciam que a aplicação de herbicidas causa toxicidade a estirpes de rizóbios ou prejudica a nodulação de leguminosas. Além disso, em alguns trabalhos (Haugland, 1994), as estirpes do gênero Rhizobium foram mais sensiveis à ação de herbicidas, comparadas a outras bactérias.

Neste trabalho objetivou-se avaliar o crescimento de duas estirpes de Rhizobium tropici
(BR 322 e BR 520) sob ação dos herbicidas bentazon, metolachlor, imazamox, fluazifop-pbutil, fomesafen e paraquat.

\section{MATERIAL E MÉTODOS}

Os trabalhos foram realizados no Laboratório de Associações Biológicas/BIOAGRO, pertencente ao Departamento de Microbiologia da Universidade Federal de Viçosa, Viçosa, MG. Foram realizados dois experimentos, sendo o primeiro visando avaliar o crescimento de duas estirpes de Rhizobium tropici (BR 322 e BR 520) em meio de cultura contendo os herbicidas (ingrediente ativo em $\mathrm{mg} \mathrm{L}^{-1}$ ): Basagran ${ }^{\circledR}$ (bentazon, 14,19), Dual Gold ${ }^{\circledR}$ (S-metolachlor 47,31), Sweeper ${ }^{\circledR}$ (imazamox 0,69), Fusilad $125^{\circledR}$ (fluazifop-p-butil 2,96), Flex ${ }^{\circledR}$ (fomesafen 4,92), Robust ${ }^{\circledR}$ (mistura pré-formulada contendo fomesafen 4,92 + fluazifop-p-butil $3,94)$ e Gramoxone ${ }^{\circledR}$ (paraquat 9,85). Utilizouse, ainda, a amostra sem adição de herbicida, totalizando 16 tratamentos, dispostos em delineamento inteiramente casualizado, com 10 repetições.

As soluções-estoque dos herbicidas foram preparadas pela mistura das formulações comerciais com água destilada e desionizada, sendo, posteriormente, esterilizadas por filtração (filtro Milipore ${ }^{\square}, 0,25 \mu \mathrm{m}$ ) em condições assépticas. As concentrações utilizadas de cada herbicida foram calculadas com base na dosagem média comercial proposta (recomendada), levando-se em consideração a área a ser aplicada.

As estirpes de Rhizobium foram obtidas da Coleção de Bactérias Diazotróficas do Centro Nacional de Pesquisa da Embrapa/Agrobiologia, sendo as culturas estocadas em meio YM composto, em $\mathrm{g} \mathrm{L}^{-1}$, por: Manitol, 10; $\mathrm{K}_{2} \mathrm{HPO}_{4}, 0,05 ; \mathrm{MgSO}_{4}, 0,02 ; \mathrm{NaCl}, 0,01$; extrato de levedura, 0,5; $\mathrm{pH}$ ajustado em 6,8 ; e à temperatura de $28{ }^{\mathrm{R}} \mathrm{C}$. A ativação destas culturas foi realizada segundo método descrito pela Embrapa (1994), sendo realizada, posteriormente, sua multiplicação em erlenmeyer de $125 \mathrm{~mL}$, com $50 \mathrm{~mL}$ de meio YM líquido, incubados em agitador rotatório a $150 \mathrm{rpm}$ e temperatura de $28{ }^{\mathrm{R}} \mathrm{C}$, até atingirem densidade óptica (DO a $560 \mathrm{~nm}$ ), equivalente a $10^{8}$ unidades formadoras de colônia (UFC) por $\mathrm{mL}$. 
O efeito dos herbicidas no crescimento das estirpes de Rhizobium foi avaliado mediante leitura da DO em espectrofotômetro (Titertek Multiskan Plus MKII), a $560 \mathrm{~nm}$. As avaliações para as primeiras 24 horas de incubação foram feitas em intervalos de duas horas. Posteriormente, até as 48 e 96 horas de incubação, os intervalos entre leituras foram a cada quatro e doze horas, respectivamente. Para isso, foram utilizadas placas de ELISA com 96 células de $300 \mu \mathrm{L}$ de capacidade volumétrica, onde foram adicionados $180 \mu \mathrm{L}$ de meio YM líquido estéril, $60 \mu \mathrm{L}$ da solução-estoque estéril dos herbicidas e $15 \mu \mathrm{L}$ das culturas ativadas, totalizando $255 \mu \mathrm{L}$ de solução. Em seguida, as placas foram incubadas no escuro, em incubadoras a $28{ }^{\circ} \mathrm{C}$, de onde foram retiradas somente para as leituras de DO, sendo imediatamente recolocadas nesse local, até o final das leituras. A transformação DO x unidades formadoras de colônia (UFC) foi obtida por meio da contagem em placas, precedida pela diluição seriada da suspensão de DO conhecida. Para interpretação dos resultados foram confeccionadas curvas de crescimento em milhões de UFC em função do tempo, sendo os dados obtidos após 96 horas de incubação submetidos à análise de variância, e as médias, comparadas pelo teste de Tukey a $5 \%$ de probabilidade.

No segundo experimento, os procedimentos para ativação, inoculação e avaliação da DO das estirpes foram semelhantes aos descritos no primeiro. Contudo, os tratamentos foram compostos pela combinação de três herbicidas (fluazifop-p-butil, fomesafen e a mistura comercial Robust ${ }^{\circledR}$, aplicados em diferentes concentrações $(0 ; 1,35 ; 3,70 ; 7,40$; 14,80; e $29,60 \mathrm{mg} \mathrm{L}^{-1}$ para o fluazifop-p-butil e $0 ; 3,08 ; 6,15 ; 12,31 ; 24,61$; e 49,23 $\mathrm{mg} \mathrm{L}^{-1}$, para o fomesafen isolado ou em mistura com o primeiro), constituindo um fatorial $3 \times 6$ para cada estirpe (BR 322 e BR 520), com 12 repetições. Os dados obtidos após 100 horas de incubação foram submetidos à análise de variância, sendo o efeito dos herbicidas sobre o crescimento das estirpes avaliado por regressão.

\section{RESULTADOS E DISCUSSÃO}

Com a aplicação dos diferentes herbicidas testados, o número de unidades formadoras de colônias (UFC) foi afetado para ambas as estirpes avaliadas. A estirpe BR 520 apresentou crescimento mais acelerado, evidenciado pela maior inclinação da fase exponencial de multiplicação celular, nas primeiras 30 horas após a inoculação (Figura 1 e Tabela 1).

Entre os herbicidas testados, o paraquat se apresentou como o produto que promoveu maior inibição do crescimento das estirpes, sendo BR 520 a estirpe mais sensivel a esse composto. A adição da mistura comercial de fluazifop-p-butil + fomesafen causou maior diminuição no crescimento da BR 322 (Figura 1).
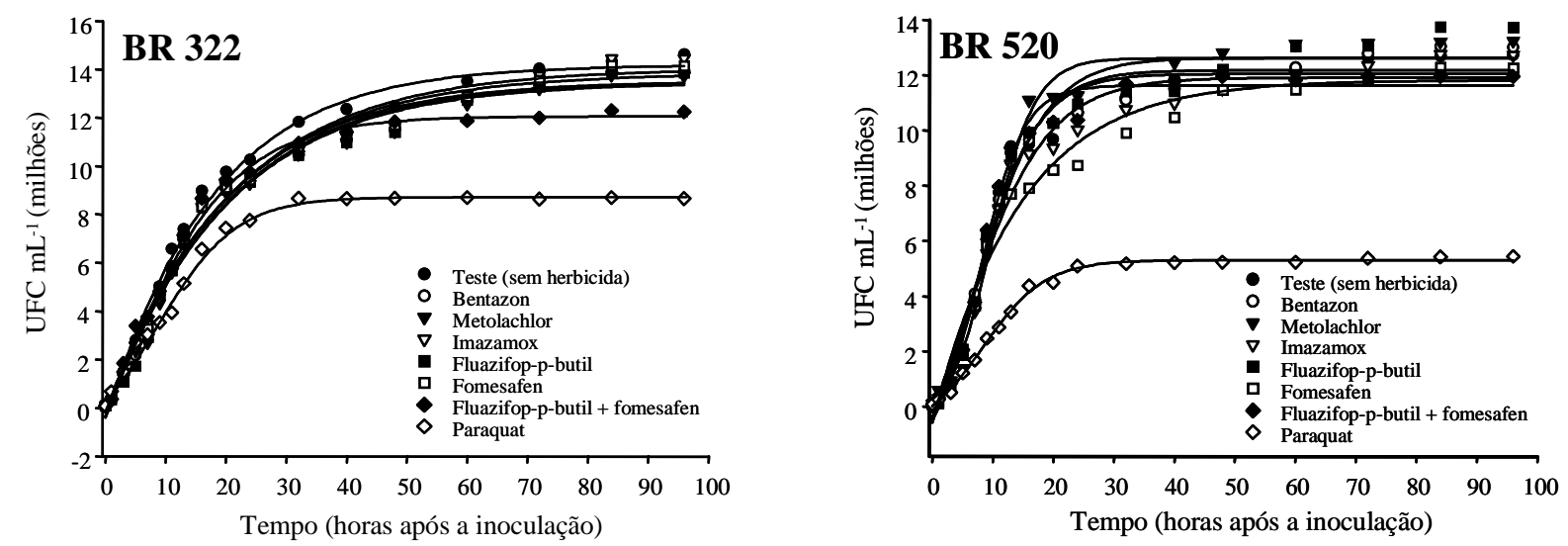

Figura 1 - Crescimento das estirpes de Rizobium tropici BR 322 e BR 520, em meio YM, sob efeito de diferentes herbicidas, ao longo de 96 horas de incubação a $28{ }^{\circ} \mathrm{C}$. Viçosa - MG, 2005. 
Tabela 1 - Equações de regressão relacionando unidades formadoras de colônia (UFC $\mathrm{mL}^{-1}$ em milhões) das estirpes de Rhizobium tropici BR 322 e BR 520 e tempo após a inoculação (horas - H), em meio YM, sob efeito de diferentes herbicidas, ao longo de 96 horas de incubação a $28{ }^{\circ} \mathrm{C}$. Viçosa-MG, 2005

\begin{tabular}{|c|c|c|}
\hline \multirow{2}{*}{ Tratamento } & Equação ajustada & $\mathrm{R}^{2}$ \\
\hline & \multicolumn{2}{|l|}{ BR 322} \\
\hline Teste (sem herbicida) & $\hat{\mathrm{Y}}=-112,0143+126,1871 /\left(1+\exp \left(-\left(\mathrm{H}^{*}+33,827\right) / 16,5951\right)\right)$ & 0,993 \\
\hline Bentazon & $\hat{Y}=-311,5169+325,0294 /\left(1+\exp \left(-\left(H^{*}+57,8269\right) / 18,5805\right)\right)$ & 0,985 \\
\hline Metolachlor & $\hat{\mathrm{Y}}=-208,7985+222,2381 /\left(1+\exp \left(-\left(\mathrm{H}^{*}+51,8617\right) / 19,1075\right)\right)$ & 0,987 \\
\hline Imazamox & $\hat{Y}=-245,0929+259,1268 /\left(1+\exp \left(-\left(\mathrm{H}^{*}+56,759\right) / 19,9297\right)\right)$ & 0,988 \\
\hline Fluazifop-p-butil & $\hat{\mathrm{Y}}=-171,9737+185,4896 /\left(1+\exp \left(-\left(\mathrm{H}^{*}+47,3315\right) / 18,8391\right)\right)$ & 0,985 \\
\hline Fomesafen & $\hat{\mathrm{Y}}=-389,2975+403,1393 /\left(1+\exp \left(-\left(\mathrm{H}^{*}+65,8382\right) / 19,796\right)\right)$ & 0,991 \\
\hline Fluazifop-p-butil + fomesafen & $\hat{\mathrm{Y}}=-13,4183+25,4747 /\left(1+\exp \left(-\left(\mathrm{H}^{*}+0,9962\right) / 10,1278\right)\right)$ & 0,996 \\
\hline \multirow[t]{2}{*}{ Paraquat } & $\hat{\mathrm{Y}}=-2,0792+10,8052 /\left(1+\exp \left(-\left(\mathrm{H}^{*}-8,0023\right) / 6,5774\right)\right)$ & 0,993 \\
\hline & \multicolumn{2}{|l|}{$\begin{array}{l}\text { BR 520 } \\
\end{array}$} \\
\hline Teste (sem herbicida) & $\hat{\mathrm{Y}}=-3,8475+15,8893 /\left(1+\exp \left(-\left(\mathrm{H}^{*}-6,8237\right) / 5,2549\right)\right)$ & 0,981 \\
\hline Bentazon & $\hat{\mathrm{Y}}=-4,0422+16,2166 /\left(1+\exp \left(-\left(\mathrm{H}^{*}-6,7038\right) / 5,4245\right)\right)$ & 0,982 \\
\hline Metolachlor & $\hat{\mathrm{Y}}=-0,906+13,5274 /\left(1+\exp \left(-\left(\mathrm{H}^{*}-9,6845\right) / 3,6682\right)\right)$ & 0,988 \\
\hline Imazamox & $\hat{\mathrm{Y}}=-8,0966+20,0066 /\left(1+\exp \left(-\left(\mathrm{H}^{*}-3,6195\right) / 7,1997\right)\right)$ & 0,977 \\
\hline Fluazifop-p-butil & $\hat{\mathrm{Y}}=-5,1199+17,7519 /\left(1+\exp \left(-\left(\mathrm{H}^{*}-6,4064\right) / 5,9944\right)\right)$ & 0,976 \\
\hline Fomesafen & $\hat{\mathrm{Y}}=-186,3582+198,1759 /\left(1+\exp \left(-\left(\mathrm{H}^{*}+37,1962\right) / 13,7308\right)\right)$ & 0,975 \\
\hline Fluazifop-p-butil + fomesafen & $\hat{\mathrm{Y}}=-1,381+12,9978 /\left(1+\exp \left(-\left(\mathrm{H}^{*}-8,1066\right) / 3,5462\right)\right)$ & 0,989 \\
\hline Paraquat & $\hat{\mathrm{Y}}=-0,9894+6,2915 /\left(1+\exp \left(-\left(\mathrm{H}^{*}-8,3666\right) / 5,1121\right)\right)$ & 0,997 \\
\hline
\end{tabular}

* Significativo pelo teste $\mathrm{t}$ a $1 \%$ de probabilidade.

Para os demais herbicidas, o efeito sobre o crescimento das estirpes foi menos significativo, chegando a aumentá-lo, no caso do fluazifop-p-butil para a estirpe BR 322 (Figura 1 e Tabela 2). Ao final do período de incubação, foi possivel observar entre os herbicidas testados, à exceção do paraquat, maior tolerância da estirpe BR 520, comparada à BR 322 (Tabela 2).

A maior toxidez apresentada pelo paraquat às estirpes de Rhizobium tropici pode estar relacionada ao seu mecanismo de ação, o qual, por meio da captura de elétrons provenientes da respiração, forma radicais tóxicos instáveis que rapidamente sofrem a auto-oxidação. Durante o processo de auto-oxidação são produzidos radicais superóxido e peróxido de hidrogênio, que reagem, produzindo hidroxil e oxigênio singlet (Weller \& Warren, 1995). Essas substâncias, juntas, promovem a degradação de membranas (peroxidação de lipídios), ocasionando a morte da célula (Weller \& Warren, 1995). Outra possivel causa para esse efeito pode ser atribuída à toxicidade de um ou mais ingredientes na formulação comercial

Tabela 2 - Crescimento relativo à testemunha (sem herbicida) das estirpes de Rhizobium tropici BR 322 e BR 520 ao longo de 96 horas de incubação a $28{ }^{\circ} \mathrm{C}$, em meio YM, sob efeito de diferentes herbicidas. Viçosa-MG, 2005

\begin{tabular}{|l|c|c|}
\hline \multirow{2}{*}{ Tratamento } & \multicolumn{2}{|c|}{ Crescimento relativo (\%) } \\
\cline { 2 - 3 } & BR 322 & BR 520 \\
\hline Testemunha (sem herbicida) & $100,00 \mathrm{a}$ A & $100,00 \mathrm{ab}$ A \\
\hline Bentazon & $95,10 \mathrm{a} \mathrm{A}$ & $102,27 \mathrm{ab}$ A \\
\hline Metolachlor & $93,88 \mathrm{a} \mathrm{B}$ & $104,03 \mathrm{ab}$ A \\
\hline Imazamox & $98,78 \mathrm{a} \mathrm{A}$ & $100,05 \mathrm{ab} A$ \\
\hline Fluazifop-p-butil & $94,69 \mathrm{a} \mathrm{B}$ & $107,93 \mathrm{a} \mathrm{A}$ \\
\hline Fomesafen & $96,73 \mathrm{a}$ A & $96,29 \mathrm{~b} \mathrm{~A}$ \\
\hline Fluazifop-p-butil + fomesafen & $83,67 \mathrm{~b}$ A & $94,02 \mathrm{~b}$ A \\
\hline Paraquat & $59,18 \mathrm{c} \mathrm{A}$ & $42,74 \mathrm{c} \mathrm{B}$ \\
\hline
\end{tabular}

Médias seguidas por letras iguais, maiúsculas na linha e minúsculas na coluna, não diferem entre si pelo teste de Tukey a 5\% de probabilidade. 
do produto. Todavia, pode ainda ter ocorrido, interação entre esses dois fatores. Santos et al. (2005) observaram que a formulação comercial do glyphosate aumentava seu efeito tóxico contra bactérias, quando comparado ao equivalente ácido puro.

O herbicida imazamox testado, semelhante ao imazethapyr, é inibidor da síntese da enzima acetolactato sintase (ALS), porém não apresentou toxidez às estirpes avaliadas. Gonzalez et al. (1996) verificaram que o $R$. leguminosarum biovar. viciae mostrou-se tolerante ao imazethapyr. Contudo, em outros trabalhos, herbicidas inibidores da enzima ALS afetaram negativamente o crescimento de estirpes de Bradyrhizobium (Arruda et al., 2001b).

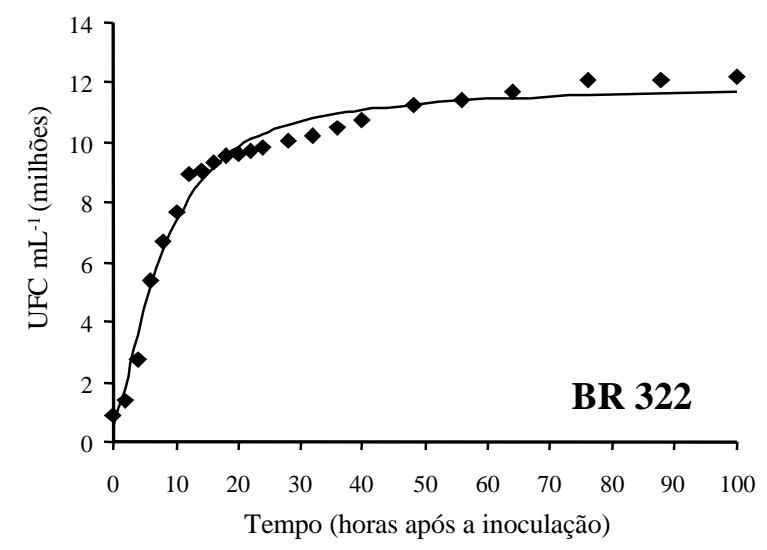

Guando o fluazifop-p-butil foi adicionado em diferentes concentrações ao meio de cultura, as estirpes avaliadas não apresentaram diferença no crescimento. Mesmo na maior concentração testada $\left(49,23 \mathrm{mg} \mathrm{L}^{-1}\right)$, o número de colônias formadas foi semelhante ao observado na testemunha, portanto, expressos por uma única regressão (Figura 2). Entretanto, com o aumento da concentração do fomesafen, isolado ou em mistura com fluazifop-p-butil, observou-se diminuição do crescimento ao longo do período de avaliação (Figuras 3 e 4 e Tabela 3). Para o fomesafen isolado, as reduções foram menores, porém mais expressivas para a estirpe BR 322 do que para a BR 520.

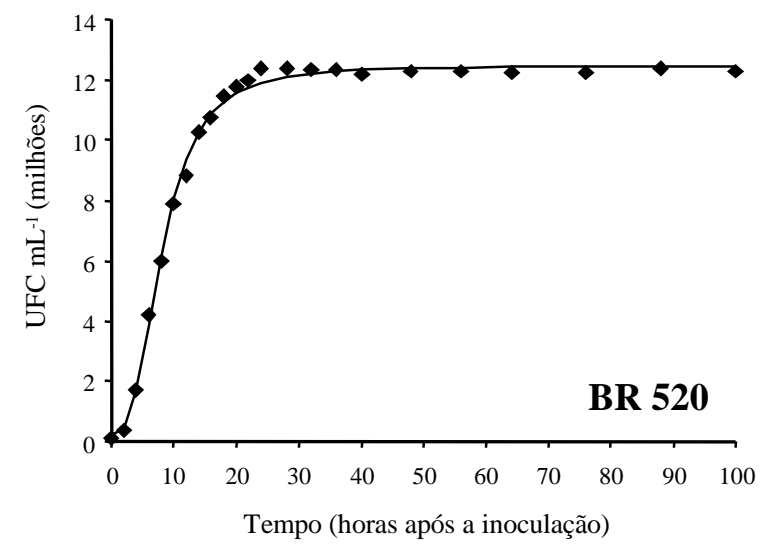

Figura 2 - Curva de crescimento das estirpes de Rhizobium tropici BR $322\left(\mathrm{v}=0,4692+11,4044 /\left(1+(\mathrm{H} / 7,5512)^{-1,568}\right.\right.$, e $\mathrm{R}^{2}=$ 0,983) e BR $520\left(\mathrm{v}=0,1994+12,2795 /\left(1+(\mathrm{H} / 8,1902)^{-2,7999}\right.\right.$, e $\left.\mathrm{R}^{2}=0,997\right)$, em meio YM, com ou sem a adição do herbicida fluazifop-p-butil em concentrações variando de 0 a 49,23 $\mathrm{mg} \mathrm{L}^{-1}$, relacionando unidades formadoras de colônias (UFC em milhões), em função do tempo (horas - H: significativo pelo teste $\mathrm{t}$ a $1 \%$ de probabilidade).
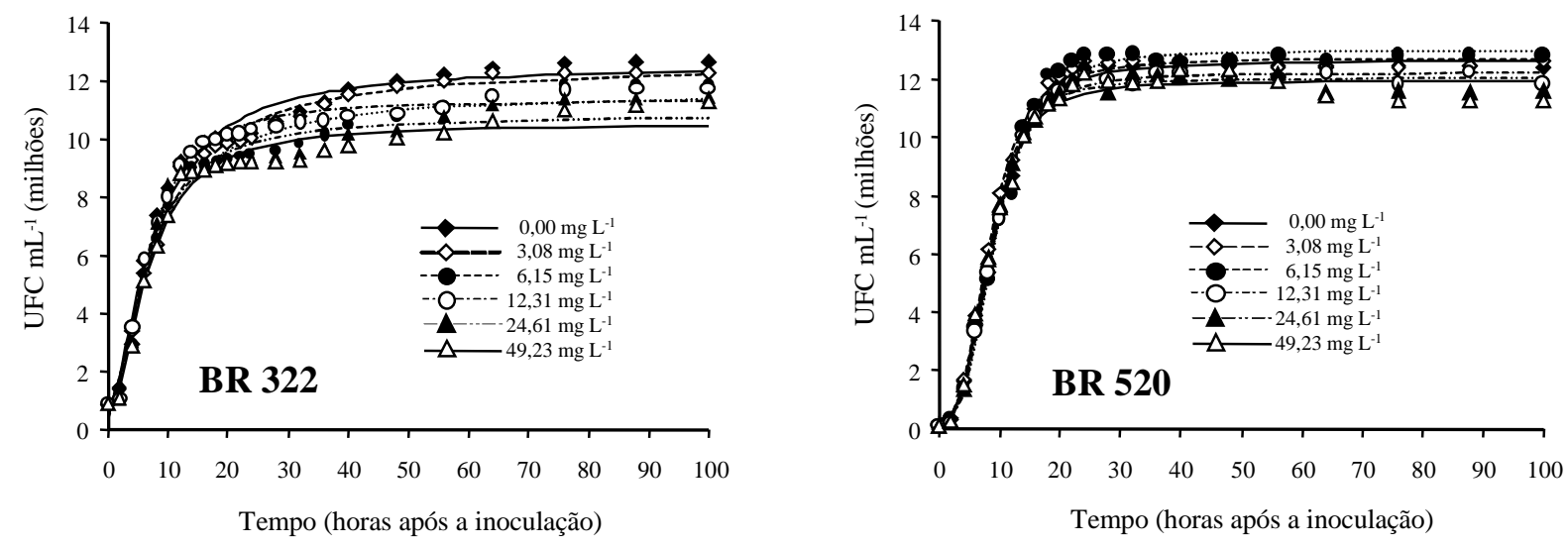

Figura 3 - Curva de crescimento das estirpes de Rhizobium tropici BR 322 e BR 520, em meio YM, com a adição de diferentes concentrações ( $\mathrm{mg} \mathrm{L}^{-1}$ ) do herbicida fomesafen, relacionando unidades formadoras de colônia (UFC em milhões), em função do tempo (horas). 

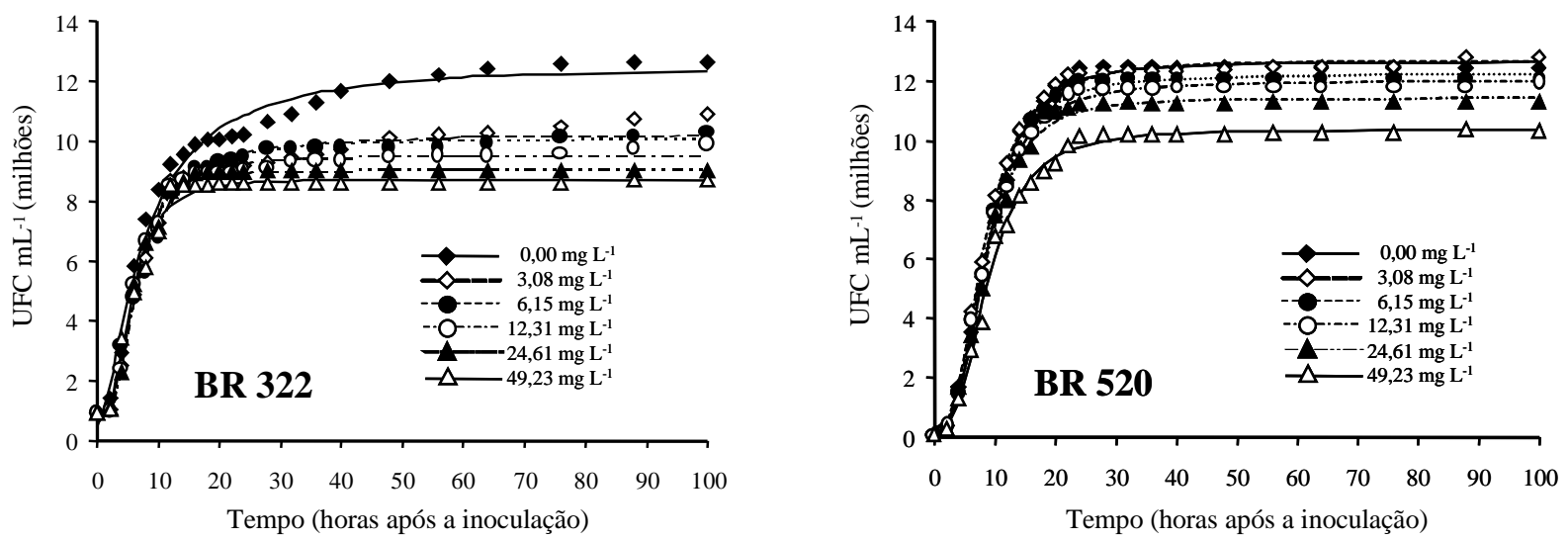

Figura 4 - Curva de crescimento das estirpes de Rhizobium tropici BR 322 e BR 520, em meio YM, com a adição da mistura préformulada dos herbicidas fomesafen $\left(250 \mathrm{~g} \mathrm{~L}^{-1}\right)+$ fluazifop-p-butil $\left(200 \mathrm{~g} \mathrm{~L}^{-1}\right)$, em diferentes concentrações $\left(\mathrm{mg} \mathrm{L}^{-1}\right)$, relacionando unidades formadoras de colônia (UFC em milhões) em função do tempo (horas).

Tabela 3 - Equações ajustadas referentes às Figuras 3 e 4. Viçosa-MG, 2005

\begin{tabular}{|c|c|c|c|c|}
\hline \multirow{2}{*}{$\begin{array}{l}\text { Fomesafen isolado } \\
\qquad\left(\mathrm{mg} \mathrm{L}^{-1}\right)\end{array}$} & Equação ajustada & $\mathrm{R}^{2}$ & Equação ajustada & $\mathrm{R}^{2}$ \\
\hline & \multicolumn{2}{|l|}{ BR 322} & \multicolumn{2}{|l|}{ BR 520 } \\
\hline 0,00 & $\hat{Y}=0,4185+12,1257 /\left(1+(H / 7,3582)^{-1,5549}\right)$ & 0,984 & $\hat{\mathrm{Y}}=0,3102+12,3191 /\left(1+(\mathrm{H} / 8,8622)^{-2,9662}\right)$ & 0,997 \\
\hline 3,08 & $\hat{\mathrm{Y}}=0,5775+11,8625 /\left(1+(\mathrm{H} / 7,9883)^{-1,5261}\right)$ & 0,992 & $\hat{\mathrm{Y}}=0,207+12,4979 /\left(1+(\mathrm{H} / 8,244)^{-2,9472}\right)$ & 0,997 \\
\hline 6,15 & $\hat{\mathrm{Y}}=0,4475+11,1482 /\left(1+(\mathrm{H} / 7,283)^{-1,5085}\right)$ & 0,997 & $\hat{Y}=0,4217+12,5402 /\left(1+(H / 9,3228)^{-3,1937}\right)$ & 0,993 \\
\hline 12,31 & $\hat{Y}=0,5248+10,8559 /\left(1+(H / 6,4343)^{-1,9012}\right)$ & 0,991 & $\hat{Y}=0,2369+11,9988 /\left(1+(H / 8,774)^{-3,1171}\right)$ & 0,996 \\
\hline 24,61 & $\hat{\mathrm{Y}}=0,3844+10,4167 /\left(1+(\mathrm{H} / 6,4388)^{-1,767}\right)$ & 0,967 & $\hat{Y}=0,1804+11,8377 /\left(1+(H / 8,1161)^{-3,1491}\right)$ & 0,993 \\
\hline \multirow[t]{2}{*}{49,23} & $\hat{Y}=0,5102+10,0035 /\left(1+(H / 6,7156)^{-1,8644}\right)$ & 0,977 & $\hat{Y}=0,2257+11,6986 /\left(1+(H / 8,1656)^{-3,0385}\right)$ & 0,990 \\
\hline & \multicolumn{2}{|l|}{$\begin{array}{c}\text { BR } 322 \\
\end{array}$} & \multicolumn{2}{|l|}{ BR 520} \\
\hline 0,00 & $\begin{array}{l}\hat{Y}=0,4185+12,1257 /\left(1+(H / 7,3582)^{-1,5549}\right) \\
\end{array}$ & 0,984 & $\hat{Y}=0,3102+12,3191 /\left(1+(H / 8,8622)^{-2,9662}\right)$ & 0,997 \\
\hline 3,08 & $\hat{Y}=0,5894+9,6304 /\left(1+(H / 6,8805)^{-2,1588}\right)$ & 0,985 & $\hat{\mathrm{Y}}=0,120+12,561 /\left(1+(\mathrm{H} / 8,2017)^{-2,6868}\right)$ & 0,987 \\
\hline 6,15 & $\hat{\mathrm{Y}}=0,7959+9,3259 /\left(1+(\mathrm{H} / 7,0645)^{-2,2643}\right)$ & 0,994 & $\hat{\mathrm{Y}}=0,1884+12,0182 /\left(1+(\mathrm{H} / 8,4264)^{-2,8254}\right)$ & 0,997 \\
\hline 12,31 & $\hat{Y}=0,7269+8,7952 /\left(1+(H / 6,2456)^{-2,7559}\right)$ & 0,994 & $\hat{Y}=0,1768+11,8204 /\left(1+(H / 8,3642)^{-2,7397}\right)$ & 0,998 \\
\hline 24,61 & $\hat{Y}=0,8415+8,2267 /\left(1+(H / 6,1209)^{-3,259}\right)$ & 0,996 & $\hat{Y}=0,275+11,1587 /\left(1+(H / 8,4769)^{-2,9957}\right)$ & 0,995 \\
\hline 49,23 & $\hat{Y}=0,8907+7,8306 /\left(1+(\mathrm{H} / 5,7968)^{-2,8241}\right)$ & 0,987 & $\hat{\mathrm{Y}}=0,1695+10,2019 /\left(1+(\mathrm{H} / 8,8735)^{-2,8137}\right)$ & 0,995 \\
\hline
\end{tabular}

${ }^{*}$ Mistura comercial Robust ${ }^{\circledR}$. H: horas, significativo pelo teste t a $1 \%$ de probabilidade.

A maior tolerância da estirpe BR 520 ficou evidente quando foram testadas diferentes concentrações da mistura comercial entre fluazifop-p-butil e fomesafen. Semelhantemente ao ocorrido no primeiro experimento, o efeito de inibição no crescimento foi menos pronunciado para BR 520 (Figura 4 e Tabela 3). Resultados em campo mostraram que o fluazifop-p-butil foi tóxico, diminuindo a massa seca e o número de nódulos em amendoim (Novo et al., 1998). A diferença na suscetibilidade de estirpes a herbicidas foi também observada por Ortiz et al. (1989), os quais concluíram que a estirpe de $B$. elkanii SEMIA 587 foi mais sensivel ao trifluralin que a SEMIA 5019 .

A possivel causa do efeito de inibição ao crescimento do fomesafen sobre o rizóbio pode ser atribuída ao seu mecanismo de ação, o qual inibe a enzima protoporfirinogênio oxidase (protox), ocasionando acúmulo celular de protoporfirina IX. Esta protoporfirina interage com o oxigênio e a luz presentes no meio, formando superóxido e peróxido de hidrogênio, 
os quais promovem a peroxidação de lipídeos, resultando em morte celular (Nandihalli \& Duke, 1993). O fato de as placas terem sido incubadas no escuro não impediu a ação do fomesafen, porque durante o tempo de cada leitura as placas eram expostas à luz (aproximadamente 20 minutos), tempo suficiente para ocorrer a ação tóxica do produto. Arruda et al. (2001a), testando o sulfentrazone - outro inibidor da protox - sobre a nodulação e a fixação do nitrogênio, verificaram que a aplicação desse herbicida em soja, em doses variando de 36 a $144 \mu \mathrm{g} \mathrm{m}^{-2}$, afetou negativamente o número e a matéria seca de nódulos formados.
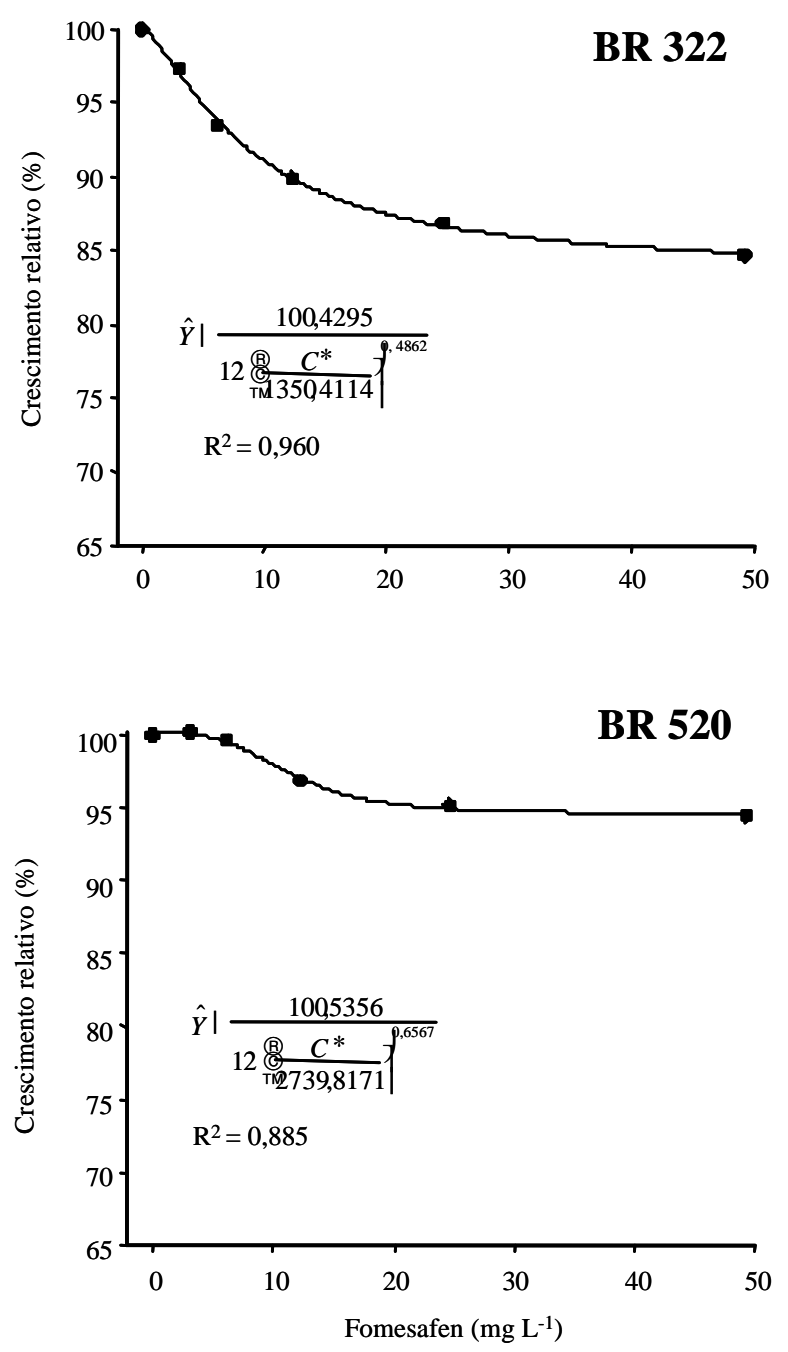

Semelhante ao comentário feito para o paraquat, também existe a possibilidade do efeito tóxico de outros compostos presentes na formulação comercial dos herbicidas sobre as estirpes de rizóbio. Santos et al. (2005) avaliaram o efeito do herbicida glyphosate puro e em formulação comercial sobre as estirpes de Bradyrhizobium SEMIA 5019, SEMIA 5079, SEMIA 5080 e SEMIA 587. Os autores observaram que o efeito tóxico era muito mais pronunciado na formulação comercial. Eles também verificaram que a adição de aminoácidos aromáticos ao meio de cultura contendo os herbicidas reduzia a toxidez para o glyphosate puro sobre as estirpes, enquanto para a

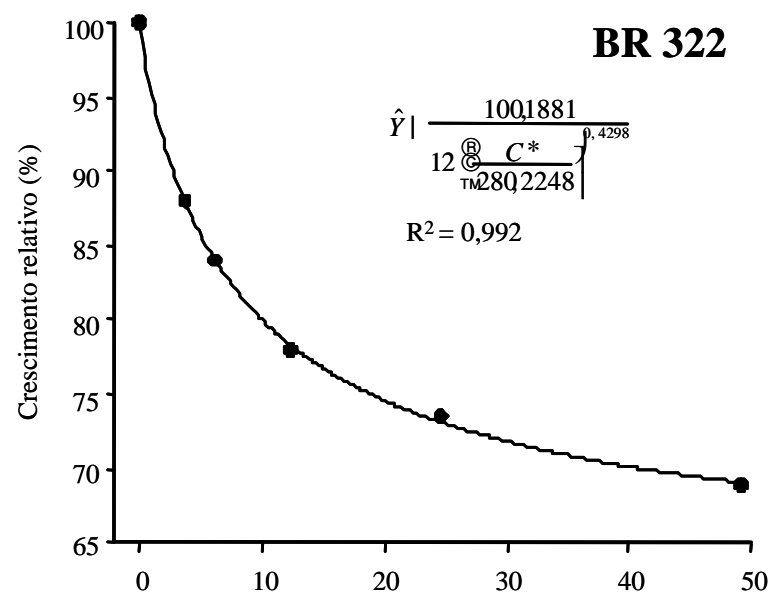

Figura 5 - Crescimento relativo (ao tratamento controle sem herbicida) das estirpes de Rizobium tropici BR 322 e BR 520 , 100 horas após a inoculação a $28^{\circ} \mathrm{C}$, em meio YM, sob efeito de diferentes concentrações dos herbicidas fomesafen e da mistura préformulada de fluazifop-p-butil + fomesafen.

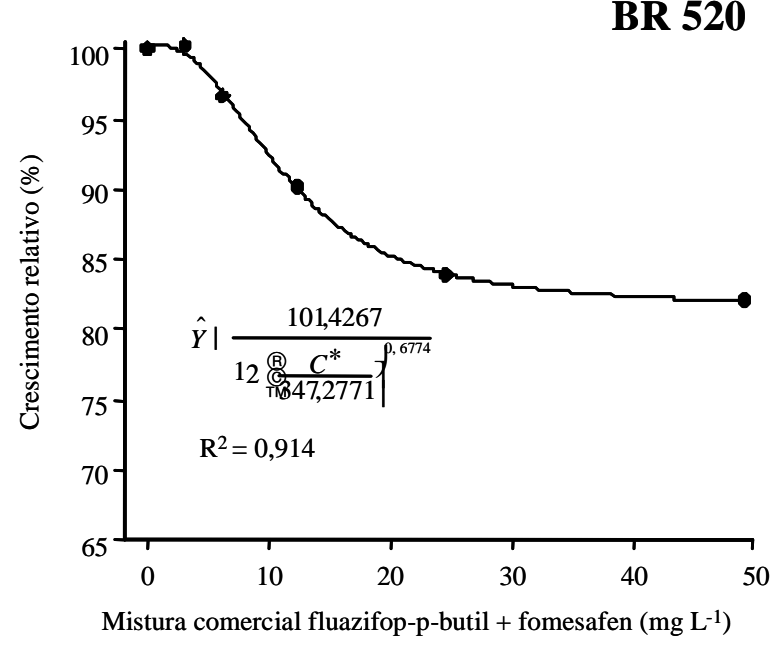


formulação Roundup Transorb ${ }^{\circledR}$ a inibição do crescimento continuava. Segundo Kishinevsky et al. (1988), é possivel que solventes, surfatantes e agentes molhantes presentes nas formulações comerciais de herbicidas contribuam para os efeitos inibitórios desses produtos no crescimento de estirpes de rizóbios. Também Malkones (2000) inferiu que os aditivos presentes na formulação dos agroquímicos podem afetar os microrganismos e, em certos casos, até modificar o efeito dos agroquímicos.

Também, no segundo experimento, ao final do período de incubação, tentou-se estabelecer a concentração dos herbicidas fluazifop-p-butil e fomesafen, responsável pela inibição de 50\% do crescimento das estirpes $\left(\mathrm{I}_{50}\right)$, porém isso não foi possivel. A maior redução do crescimento verificada foi de $31,1 \%$ para a estirpe BR 322, sob ação da mistura comercial de fluazifop-p-butil e fomesafen $\left(49,23 \mathrm{mg} \mathrm{L}^{-1}\right)$ (Figura 5). Reduções acima de 50\% foram constatadas por Santos et al. (2004) em três estirpes de Bradyrhizobium, que receberam o herbicida glyphosate em concentração abaixo de $10 \mathrm{mg} \mathrm{L}^{-1}$. Também os herbicidas imazethapyr e fomesafen aplicados em meio YM para o crescimento de Bradyrhizobium elkanii (SEMIA 5019) reduziram em mais de $40 \%$ o crescimento dessa estirpe (Procópio et al., 2004).

Em geral, pode-se afirmar que o herbicida fomesafen aplicado isoladamente ou em mistura com fluazifop-p-butil promove efeito negativo sobre o crescimento das estirpes avaliadas, sendo esse efeito diretamente proporcional à concentração desse produto em meio de cultura. Entretanto, seu efeito é menor do que o observado para o paraquat. Entre as estirpes de $R$. tropici avaliadas, BR 520 se mostrou mais tolerante aos herbicidas testados, sendo, normalmente, aquela com maior potencial para utilização em campo.

\section{AGRADECIMENTOS}

Ao Centro Nacional de Pesquisa da Embrapa/Agrobiologia, pelo fornecimento das estirpes de rizóbio; e ao CNPq, pelo apoio financeiro para a realização deste trabalho.

\section{LITERATURA CITADA}

ARRUDA, J. S.; LOPES, N. F.; BACARIN, M. A. Nodulação e fixação do dinitrogênio em soja tratada com sulfentrazone.

Pesq. Agropec. Bras., v. 36, n. 2, p. 325-330, 2001 a.
ARRUDA, J. S.; LOPES, N. F.; MOURA, A. B. Behavior of Bradyrhizobium japonicum strains under different herbicide concentrations. Planta Daninha, v. 19, n. 1, p. 111-117, 2001b.

EBERBACH, P. L.; DOUGLAS, L. A. Herbicide effects on the growth and nodulation potential of Rhizobium trifolii with Trifolium subterraneum. Plant Soil, v. 119, n. 1, p. 15-23, 1989.

EMPRESA BRASILEIRA DE PESQUISA AGROPECUÁRIA - EMBRAPA. Centro Nacional de Pesquisa de Arroz e Feijão. Manual de métodos empregados em estudos de microbiologia agrícola. Brasília: 1994. 542 p.

GONZALEZ, A.; GONZALEZ-MURUA, C.; ROYUELA, M. Influence of imazethapyr on Rhizobium growth and its symbiosis with pea (Pisum sativum). Weed Sci., v. 44, p. $31-37,1996$.

HAUGLAND, E. Ecological consequences of chemical weed control. Norsk Landbruksfor., v. 8, n. 1, p. 1-13, 1994.

KISHINEVSKY, B. et al. Effects of some commercial herbicides on rhizobia and their symbiosis with peanuts. Weed Res., v. 28, p. 291-296, 1988.

MALKONES, H. P. Comparison of the effects of differently formulated herbicides on soil microbial activities a review. J. Plant Dis. Prot., v. 8, n. 5, p. 781-789, 2000.

MALLIK, M. A. B.; TESFAI, K. Pesticidal effect on soybean-rhizobia symbiosis. Plant Soil, v. 85, n. 1, p. 33-41, 1985.

MARENCO, R.; LOPES, N. F.; MOSQUIM, P. R. Nodulation and nitrogen fixation in soybeans treated with herbicides. R. Bras. Fisiol. Veg., v. 5, n. 2, p. 121-126, 1993.

MENDES, I. C. et al. Efeito da inoculação com rizóbio e da adubação nitrogenada em sete cultivares de feijão em solo de cerrado. R. Bras. Ci. Solo, v. 18, p. 421-425, 1995.

MOORMAN, T. B. et al. Production of hydroxybenzoic acids by Bradyrhizobium japonicum strains after treatment with glyphosate. J. Agric. Food Chem., v. 40, n. 2, p. 289-293, 1992.

NANDIHALLI, U. B.; DUKE, S. O. The porphyrin pathway as a herbicide target site. In: DUKE, S. O.; MENN, J. J.; PLIMMER, J. R. (Ed.). Pest control with enhanced environmental safety. Washington: American Chemical Society, 1993. p. 62-72. (American Chemical Society Symposium Series, 524).

NOVO, M. C. S. S. et al. Efeito de linuron e oryzalin no crescimento da planta, na fixação simbiótica do nitrogênio e na produtividade da soja. Planta Daninha, v. 14, n. 1, p. 65-81, 1996. 
NOVO, M. C. S. S. et al. Influência de herbicidas aplicados em condições de pós-emergência no crescimento da planta e fixação simbiótica do nitrogênio na cultura do amendoim. Sci. Agríc., v. 55, n. 2, p. 276-284, 1998.

ORTIZ, S.; MUSUMECI, M. R.; TSAI, S. M. Efeito de alguns agrotóxicos na sobrevivência e na atividade respiratória de Rhizobium leguminosarum e

Bradyrhizobium japonicum. Pesq. Agropec. Bras., v. 24, n. 6, p. 663-667, 1989.

PROCÓPIO, S. O. Crescimento de estirpes de Bradyrhizobium sob influência dos herbicidas glyphosate potássico, fomesafen, imazethapyr e carfentrazone-ethyl. R. Ceres, v. 51, n. 294, p. 179-188, 2004.

ROYUELA, M. et al. Imazethapyr inhibition of acetolactate synthase in Rhizobium and its symbiosis with pea. Pestic. Sci., v. 52, p. 372-380, 1998.
SANTOS, J. B. et al. Efeitos de diferentes formulações comerciais de glyphosate sobre estirpes de Bradyrhizobium. Planta Daninha, v. 22, n. 2, p. 293-299, 2004.

SANTOS, J. B. et al. Tolerance of Bradyrhizobium strains to glyphosate formulations. Crop Prot., v. 24, p. 543-547, 2005.

SCHULZ, A.; KRÜPER, A.; AMRHEIN, N. Differential sensitivity of bacterial 5-enolpyruvylshikimate-3-phosphate synthases to the herbicide glyphosate. FEMS Microbiol. Let., v. 28, n. 3, p. 297-301, 1985.

SILVA, A. A. et al. Controle de plantas daninhas. Brasília: ABEAS, módulo 3, 2003. 260 p.

WELLER, S. C.; WARREN, G. F. Superoxide generators and protoporphyrinogen oxidase inhibitors (Paraquat and Diquat). In: HERBICIDE action course. West Lafayette: Purdue University, 1995. $787 \mathrm{p}$. 